\title{
Old rus family diet: plants
}

\begin{abstract}
This paper presents the results of research palaeo-botanic archaeological artifacts obtained during the study of ancient habitation XII. Perfect safety of these samples made it possible to reconstruct the plant food diet medieval era Old Russian family in a short season.
\end{abstract}

Keywords: Ukraine, manzheliya, fort, old period paleobotanists
Volume 3 Issue I - 2018

\author{
Vyacheslav V Sherstiuk,' Sergey A \\ Horbanenko² \\ 'Department of Culture Poltava's Regional State Administration, \\ Ukraine \\ ${ }^{2}$ Institute of Archaeology, Ukraine
}

\begin{abstract}
Correspondence: Vyacheslav V Sherstiuk, Department of Culture Poltava's Regional State Administration, Ukraine, Email666sher@gmail.com
\end{abstract}

Received: June 02, 2017| Published: January 24, 2018

\section{Introduction}

In 2016 Manzheliyivska expedition Health Center and archaeological research (c. Poltava) continued research and rescue archaeological survey of the construction site of ancient settlement time and Cossack time around with. Manzheliya Globinskiy a Poltava region, Ukraine (Figure 1), started last year. The objects of the study were complex from 17 th to early 18 th century which remains blocked Cabin middle - the second half of the 12th century. Paleobotanical materials obtained in this study represent the subject of this work. Old Rus little house carcass structure (now excavated only part of the central section of the strip and one wall). It was died due to sudden fire. The fact that abandoned building was in a hurry when some catastrophe (probably nomadic attack) is not in doubt because of the large richness of archaeological artifacts and their "ordering" relatively planografi facilities. So materials retained their spatial position in situ. And with fire walls and falling asleep next pit housing passage pyrolysis process without oxygen, the said organic remains was equipped with the maximum degree of preservation and conservation (especially artifacts under the walls of buildings).

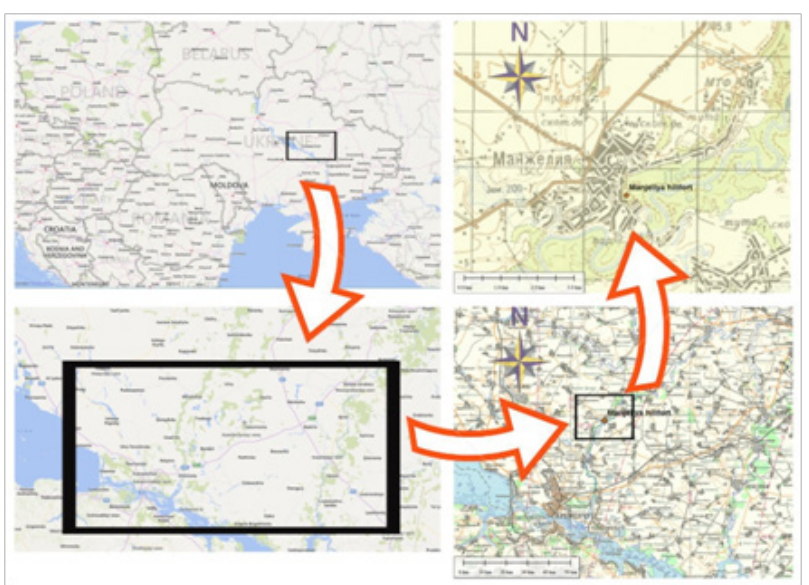

Figure I Map locations Manzheliyivskoho settlement (http://wikimapia.org).

In addition palaeobotanic materials to backfill definite object was investigated in a large number of ceramic kitchen containers. Some of them on fire mistla remains of food (mainly poultry), used to ferment and dyeing wool, etc. (Figure 2). Hence, large selection of tree-bark utensils and many of the subjects of this type was restored and the next made copies, replicas of artifacts (Figure 3). This cooper's naborni tray, chiseled and carved plates, saucers, buckets, spoons, cup, and numerous remains of woven birch bark containers. Note that a number of these vessels birch-tree is used to store the products described in this publication (as it is on). The vast majority of materials paleobotanical nature occurred during the study of the internal structure, over-felling wall housing. Here were discovered the most massive cluster of most of the submitted samples, largely on or between the collapses the de-Revo birch vessels (Figure 4).

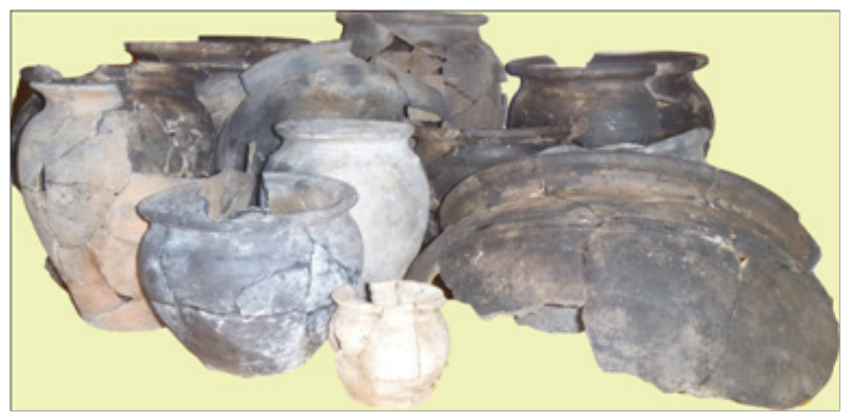

Figure 2 Ceramic tableware with housing.

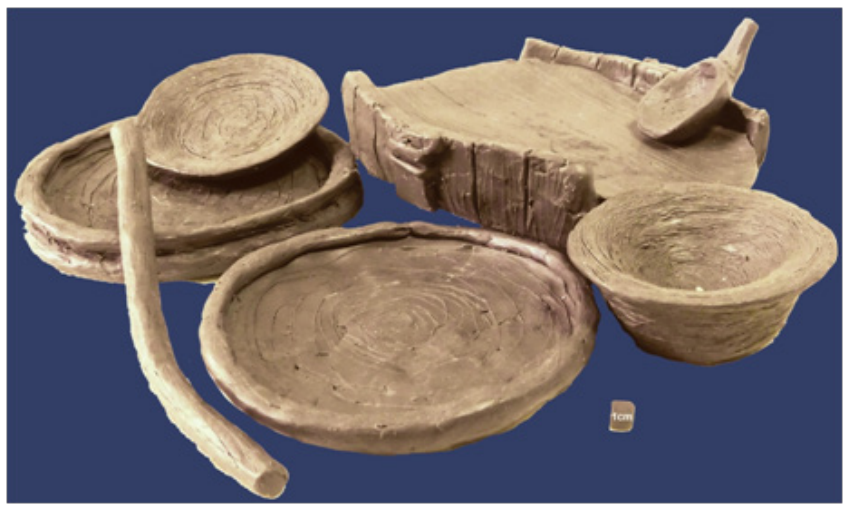

Figure 3 Wood products, Reconstruction, Plasticine.

The lower part of the materials came from the central sector of housing (in the absence of another wall, this part is called conditionally central) area near collapse of adobe oven. This cluster, received so 
called "bag of millet" and floating materials from this part used to fill housing. Paleobotanical materials (Figure 5), Organic materials have exceptionally good property preservation. In this connection, a meeting paleobotanical flotation material had special meaning: saturation filling small coals housing is extremely high, which is almost impossible for finding crops. Looking ahead flotation unit received copies of the same cultures without the use of the method were selected in large numbers during manual sampling. However, it received a significant amount of coals, which greatly complement their database of settlement selected manually. Almost all bases with paleobotany settlement remains are now obtained during the manual selection remains to fill different parts of residential buildings. Materials from these objects collected from various excavation squares, mostly at the bottom, natural preservation of sample on a 5 -point scale of 5 points.

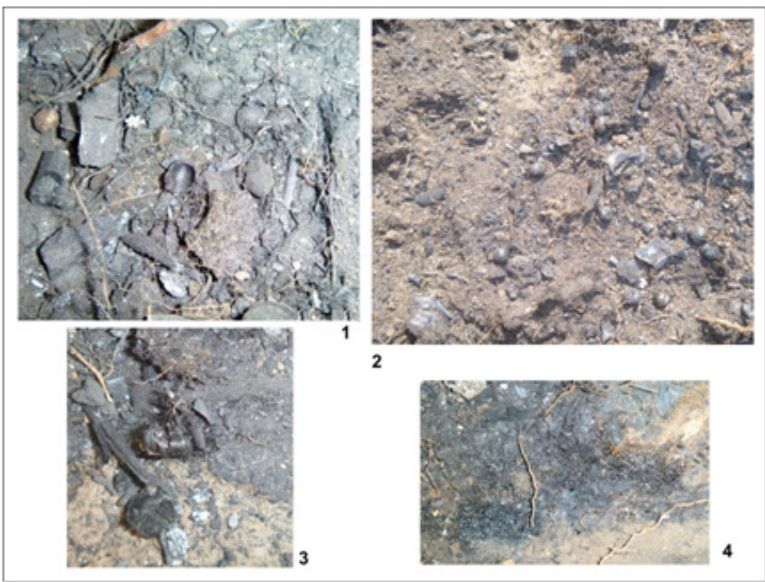

Figure 4 Part paleoethnobotanical material in situ: I, Cherry; 2, Peas; 3, Calendula; 4, Millet.

Materials derived from multiple clusters. One of clusters found in linen sacks, the remains of which are also able to collect. We had well preserved, with a diameter of 2-3 $\mathrm{mm}$, are sowing millet (Panicum miliaceum). All grain is cleaned of films. From the nearby sample

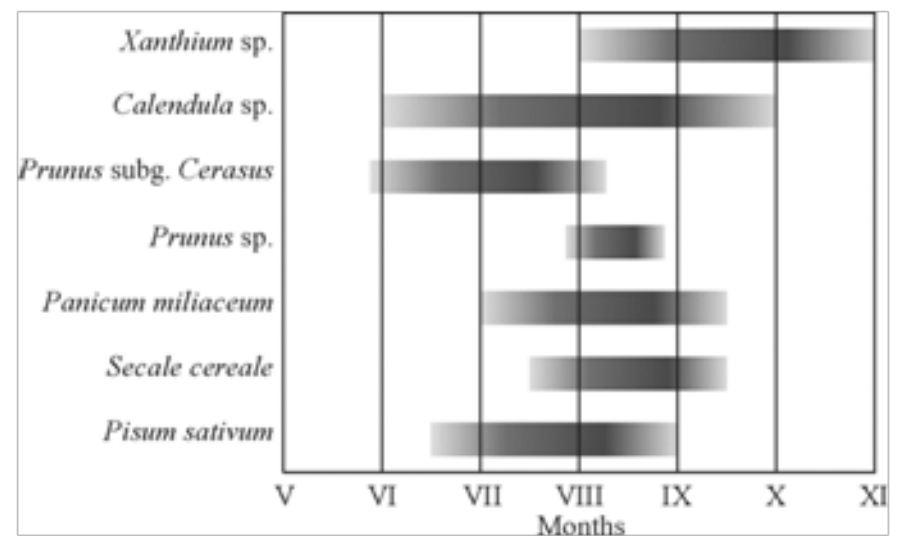

bag millet crude comes as scales in the breast. There also comes a mixture of fragmented materials consisting of pea (Pisum sativum), some caryopsides treated millet and rye (Secale cereale). Pea seeds in large quantities with large size also found in the squares B1 and B3. The material present millet crude is a roast breast of scales. From the same sample we derived fragmented bones cherries (Prunus subg, Cerasus) and plums (Prunus sp.). Also found several joints stems from cultural grain.

Separately in a crowded collapse woven birch bark vessels found Netreba fruit (Xanthium sp.) and flowers like aster (Asteraceae), probably marigold (Calendula sp.). Seeds of peas from different samples did not differ among themselves. Some are represented halves its diameter (10 measurements) of $5.3 \mathrm{~mm}$. The counting number of paleobotanical materials is meaningless. Since this will lead to provide obvious conclusion about the cultivation of peas, millet and rye, gardening or collecting cherries and plums, as well as collecting and Netreba (probably as medicinal plants). A sample of the sack has clear signs of breeding material. Among other samples, studied millet only represented grains, free of scales. That is, due to its grits, prepared for cooking. Here and placed beside a bag of untreated grains. Pea represented mostly good large seeds. Another interesting fact that two seeds probably uncovered fragments belong to some wooden vessels and the find represents a complex in situ: peas, situated on or in a wooden container at the time archeological object. Still it is difficult to solve the issue of the level of gardening during ancient. We believe that this is due to several reasons, first of all - fixing capacity remains from garden trees, probably because archeological materials could only a short period of use. In contrast to the "standard" paleobotanical materials could get into the archaeological materials throughout the year. Despite addressing "global" issue of implementation of gardening, it is obvious that ancient settler's fort cherry and plum were like. Regardless of whether it was a form of wild or domesticated. Also very interesting fact about Netreba is that it is a Buryanov plant distributed throughout the territory of Ukraine grows on moist sandy soil along rivers, near fences, roads, pastures, crops in crops. ${ }^{1}$ The different parts of plants have many medicinal properties used to treat various diseases and is widely used in folk medicine. ${ }^{2}$

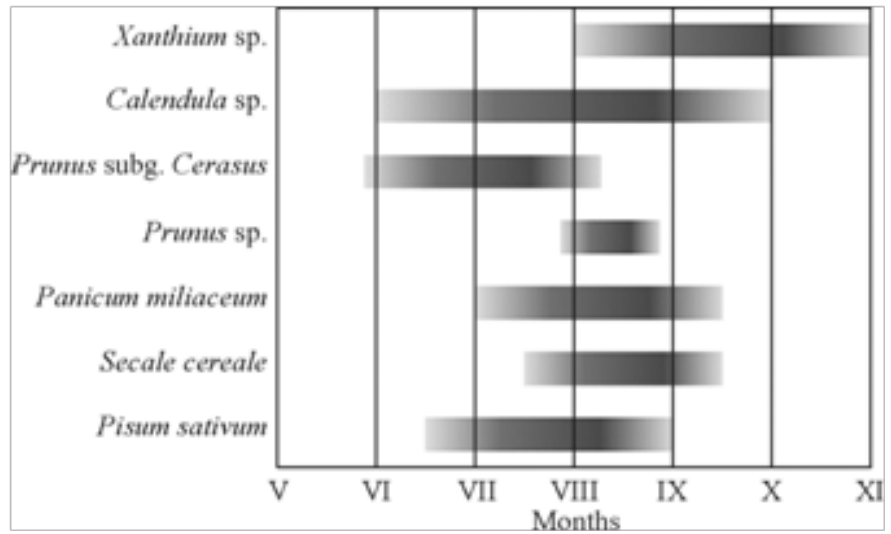

Figure 5 Paleoethnobotanical materials: I, Millet; 2, Rye; 3, Peas; 4, Cherry; 5, Plum; 6, Netreba; 7, Calendula.

\section{Conclusion}

Thus, it is obvious that the ancient inhabitants of the settlement will use all opportunities which are available to them and the reproduction of natural resources (agriculture, horticulture. Also by comparing the harvest period archeological gets paleobotanical materials which can be described as part of August (Figure 6). 


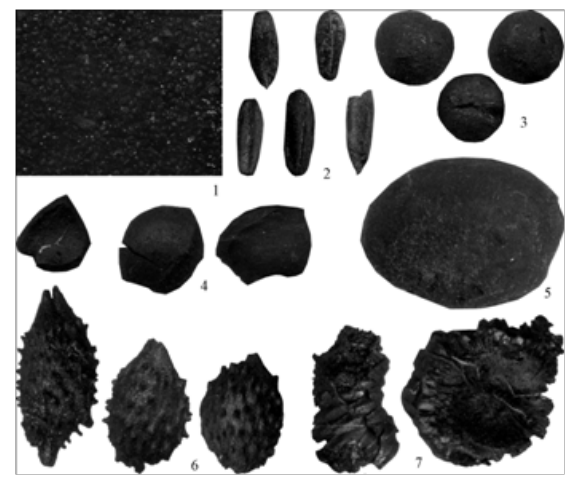

Figure 6 The period of maturation and harvesting of plants found in home.

\section{Acknowledgements \\ None.}

\section{Conflict of interest}

Author declares that there is no conflict of interest.

\section{References}

1. Veselovsky IAK, Manko JP. Atlas determinant weeds. In: Harvest K, editor. Vintage Botanical Book, Urozhay. Russia; 1988. p. 72.

2. Chopyk VI, Dudchenko LG, Dykorastuschye K. Useful plants of Ukraine. Ukraine; 1983. p. 400. 